\title{
BMJ Open Learning a new way of living together: a qualitative study exploring the relationship changes and intervention needs of patients with cardiovascular disease and their partners
}

\author{
Heather Tulloch (1) , ${ }^{1}$ Karen Bouchard, ${ }^{1}$ Matthew J Clyde, ${ }^{1}$ Lorenzo Madrazo, ${ }^{2}$ \\ Natasha Demidenko, ${ }^{3}$ Susan Johnson, ${ }^{4}$ Paul Greenman ${ }^{5}$
}

To cite: Tulloch $\mathrm{H}$, Bouchard $\mathrm{K}$, Clyde MJ, et al. Learning a new way of living together: a qualitative study exploring the relationship changes and intervention needs of patients with cardiovascular disease and their partners. BMJ Open 2020;10:e032948. doi:10.1136/ bmjopen-2019-032948

- Prepublication history for this paper is available online. To view these files, please visit the journal online (http://dx.doi. org/10.1136/bmjopen-2019032948).

Received 13 July 2019

Revised 09 February 2020

Accepted 30 March 2020
Check for updates

(C) Author(s) (or their employer(s)) 2020. Re-use permitted under CC BY-NC. No commercial re-use. See rights and permissions. Published by BMJ.

For numbered affiliations see end of article.

Correspondence to Dr Heather Tulloch; hetulloch@ottawaheart.ca

\section{ABSTRACT}

Objectives Cardiovascular disease (CVD) not only affects the patient, but has implications for the partner. Emerging evidence suggests that supportive couple relationships enhance CVD outcomes and reduce patient and partner distress. To date, however, little research has been done to address the couple relationship as a potentially important component of cardiac care. This article examines the impact of CVD on the couple relationship and assesses the perceived needs and desired intervention components of patients with CVD and their partners.

Design Qualitative study using directed and conventional content analysis.

Setting Single-centre, tertiary cardiac care hospital that serves a population of 1.4 million in the Champlain region of Ontario, Canada.

Participants Patients with CVD and their partners $(n=32$, 16 couples) participated in focus groups. Patients were mainly male $(75 \%)$, white $(87.5 \%)$, aged 64.4 years (range 31-81 years), with varied cardiac diagnoses (50\% coronary artery disease; $18.75 \%$ valve disease; $18.75 \%$ heart failure; $12.5 \%$ arrhythmia).

Results Five categories were generated from the data reflecting changes within the couple relationship as a result of CVD: (1) emotional and communication disconnection; (2) overprotection of the patient; (3) role changes; (4) adjustment to lifestyle changes; and (5) positive relationship changes. Three categories were constructed regarding intervention needs and desired resources: (1) practical resources; (2) sharing with peers; and (3) relationship enhancement.

Conclusions Overall, the data suggest that there were profound changes in the couple relationship as a result of CVD, and that there is considerable need to better support the caregiving spouses and the couple as a unit. These results call for interventions designed to provide instrumental support, peer-sharing opportunities and relationship quality enhancement to help couples cope with CVD. Future studies should examine whether couplesbased programming embedded into cardiac rehabilitation can be effective at improving relationship quality and reducing patient and partner stress in the aftermath of a cardiac event
Strengths and limitations of this study

- This study is the second, to our knowledge, to explore potential areas of intervention for couples in which one partner has cardiovascular disease (CVD).

- The Obesity-related behavioral intervention trials (ORBIT) model for developing behavioural treatments for chronic diseases was employed.

- Generalisability is limited by recruitment at one site, mainly male patients, and heterosexual couples.

- The findings cannot reveal how couples' needs may change over time as the focus groups were conducted at one time point.

The unique needs of specific CVD diagnostic groups were not analysed due to limited sample size.

\section{INTRODUCTION}

Cardiovascular disease (CVD) is a leading cause of mortality in most western nations. Multiple modifiable risk factors for CVD have been identified, including smoking, physical inactivity, hypertension, poor diet, metabolic syndrome and stress. These factors are routinely targeted in primary and secondary prevention programmes, which reduce morbidity and mortality, and improve mental health and quality of life outcomes among patients with CVD. ${ }^{1}$ Interestingly, despite the well-established link between social relationships and the progression of $\mathrm{CVD},{ }^{2}{ }^{3}$ this component is rarely targeted in the prevention or management of CVD. ${ }^{4}$

Accumulating evidence indicates that positive social relationships are integral to health. To illustrate, a meta-analysis with over 300000 participants revealed an increased survival rate of $50 \%$ for those in supportive relationships. ${ }^{3}$ Socially isolated individuals or those in poor relationships, in contrast, experience increased morbidity and mortality. 
For example, a $29 \%$ increased risk of coronary artery disease was reported in a recent meta-analysis including over 35000 participants. ${ }^{2}$ Given the importance of intimate relationships for most adults, it is not surprising that partner support is the strongest determinant of well-being relative to other sources of support. ${ }^{5}$ In fact, a recent systematic review revealed that simply being married is associated with fewer CVD risk factors and improved survival rates. ${ }^{6}$ One cohort study with almost one million patients with acute coronary syndrome, for example, detected lower mortality rates for married $(\mathrm{OR}=0.86)$ and widowed patients $(\mathrm{OR}=0.96)$, whereas single patients had increased rates $(\mathrm{OR}=1.07){ }^{7}$

Other evidence indicates, however, that the quality of the relationship, not just its presence, may dictate the impact on heart health. High-quality relationships are characterised by high relationship satisfaction, warmth, support and closeness, while distressed relationships exhibit high levels of conflict, hostility, distance and dissatisfaction. ${ }^{8}$ The presence of strong patient-partner relationships, high in relationship quality, has been associated with improved physical and mental health outcomes. Marital discord, in contrast, has been related to elevated risk of CVD development and to the progression of established disease, even when other risk factors such as age, blood pressure and body mass index are controlled for in the analyses. ${ }^{10-13}$ For example, one study found that the survival rates of patients who underwent coronary artery bypass surgery and reported satisfying relationships were three times higher than those in poor relationships. ${ }^{14}$ Hypertension and increased heart rate are observed with marital conflict, ${ }^{1516}$ whereas reductions in blood pressure are observed during supportive interactions. ${ }^{17}$ Patients in well-adjusted relationships are more likely to adhere to medical prescriptions and to be more assiduous in their attendance at cardiac rehabilitation. ${ }^{18} 19$ There is evidence that high quality patient-partner relationships can also reduce caregiver burden, distress and depressive symptoms. ${ }^{20}$ Taken together, the evidence connecting poor patient-partner relationship quality to deleterious physical and mental health outcomes continues to mount, whereas high-quality relationships appear to buffer the impact of CVD and to enhance physical and mental health.

Despite this evidence, few interventions for cardiac patients and their partner exist. To date, the focus, not surprisingly, has been on traditional CVD risk factors such as exercise, diet and smoking behaviour. A systematic review of seven couples-based psychological interventions for patients with coronary artery disease reported modest improvements in patients' knowledge of disease and treatment, blood pressure and quality of life with intervention participation, but no effect on morbidity or mortality. ${ }^{4}$ Low-quality methods were thought to explain the reduced efficacy. Methodological limitations of couples-based interventions include: outdated studies-many are over 20-year old and the medical care and related couple experience has changed substantially; interventions were not based in theory or were simply informational; small sample sizes; and data collection has been restricted to the patient and lacked measures of relationship quality. ${ }^{41-23}$ Further, to our knowledge, only one study in the CVD context has targeted the couple relationship as an intervention component to date. ${ }^{24}$ Results of that study demonstrated improvements in exercise levels, but distressed couples did not maintain gains at intervention completion (18 weeks). A more targeted intervention aimed to improve relationship quality may be required to enhance couple-related, psychological, behavioural and physical health outcomes.

In order to design more effective couples-based interventions, an in-depth understanding of the experience and needs of patients and partners in the context of CVD is required. Dalteg et al systematically reviewed qualitative and quantitative research investigating the impact of cardiac disease on the partner relationship. ${ }^{25}$ Results indicated that the impact is extensive and distressing on multiple levels, including adjustment to illness and role changes, sexual concerns and communication and overprotection. Unfortunately, the studies included in the review are now a decade old and, like the intervention research described above, they preclude a contemporary impression of the dyad's experience in the current medical environment. Since this review, ${ }^{25}$ to our knowledge, six additional studies in the cardiac context were published. ${ }^{26-31}$ Findings highlighted difficulties living with the uncertainty of the disease and managing lifestyle changes, feelings of worry and vigilance, and caregiver burden and support. Patients and partners also reported that caring involvement brought the couple closer together or, the opposite, a feeling of loss of the partner relationship and role changes. These studies, however, included select cardiac populations (ie, patients with atrial fibrillation or heart failure), spouses only or family members other than spouses, or focused on dyadic coping regarding lifestyle changes only. Further, only one ${ }^{32}$ of the previously reviewed ${ }^{25}$ or newer studies inquired about potential areas of support for the patientpartner dyad. With approximately $30 \%$ of couples with CVD reporting marital discord ${ }^{33}$ and the potential physiological detriment on patients' cardiovascular health, more research on the experience and intervention needs of patients with CVD and their partners is required. This information may then be used to enhance intervention development and efficacy.

Employing a systematic framework, such as the Obesityrelated behavioral Intervention trials (ORBIT) model for developing behavioural treatments for chronic diseases, ${ }^{34}$ has been shown to produce stronger behavioural treatments and to avoid costly trials of those that have not been optimised. Phase I (design and define) aims to identify the essential features of a treatment. Qualitative research is often employed to engage the community of participants and reveal details of the clinical problem and potential treatment components. Practical aspects of the intervention are also investigated, including, for 
example, the preferred mode of delivery, setting and frequency and duration of contact. With this information, an intervention that is acceptable to the target population and has promise for clinically significant benefit can be created. This phase is followed by preliminary testing such as proof of concept trials (phase II) and, if positive results are detected, an randomised controlled trial (RCT) pilot study is then justified. Efficacy testing in the form of larger RCTs (phase III) and effectiveness research (phase IV) complete the process.

The present study describes phase I for the development of a couples-based intervention for patients with CVD and their partners. The specific aims were: (1) to further understand the impact of CVD on the nature of the couple relationship and (2) to assess the intervention needs and desires of patients with CVD and their partners, including an exploration of their interest in a couples-based intervention in cardiac rehabilitation. The ultimate goal was to inform the development of relevant cardiac interventions that involve the couple as a unit.

\section{METHODS}

\section{Design and setting}

This study used an exploratory and qualitative design. The study was carried out at the University of Ottawa Heart Institute in Ottawa (UOHI), a quaternary care cardiac hospital that serves a population of 1.4 million in the Champlain region of Ontario, Canada.

\section{Participant recruitment}

All participants were past or current participants of the UOHI cardiac rehabilitation programme; no restrictions were placed on cardiac diagnosis. Patients were recruited using purposive sampling from UOHI cardiac rehabilitation classes by one of the researchers (HT). Announcements were made stating, 'we recognise that dealing with a heart condition can be difficult for patients and their significant others. We are recruiting patients and their partners to participate in a focus group meeting so that we might better understand your experiences, concerns and needs with heart disease. Our goal is to improve the services we offer to the patients and their spouses'. Interested patients approached the researcher who then screened them for eligibility and, if eligible, scheduled them for a focus group session. Participants were included if they had directly or indirectly (ie, through a spouse) experienced a cardiovascular event, were in a couple relationship (married, common law, or in a committed relationship for $\geq 2$ years), were 18 years of age and older, and were able to speak English. There were no exclusion criteria for this study.

\section{Focus group interviews}

Patients were invited to attend a 1.5 hour focus group with their partner. Focus groups were particularly suited for this study as it allowed for interactive and intensive discussions among both patients and partners. Furthermore,

\section{Box 1 Focus group sample questions}

1. Sometimes people say that heart disease brings them closer together. Other times they say that it just seems to create more problems and stresses on top of the ones they already have. How has your experience been?

2. A lot of times patients and partners see heart disease differently. How similar or different would you say your perspectives on having heart disease are?

3. What has been the most difficult part of having heart disease (or having a partner with heart disease)?

4. How could the Heart Institute help you and your significant other cope better together? What have you found most helpful so far?

5. Would you be interested in a couples-based intervention as part of cardiac rehabilitation? If so, what would it look like?

focus groups position participants as experts of their social worlds and can help to reduce unequal power relations among the researchers and participants that can manifest in individual interviews. ${ }^{35}$ All focus groups took place in meeting rooms at the UOHI; only the participants and the interviewers were present. A semistructured interview guide was used throughout the focus groups. Question development was guided by the clinical expertise of the investigators, analyses of transcripts of couple therapy sessions with heart patients and previous research on couples and CVD. ${ }^{25}{ }^{36} 37$ Box 1 provides a sample list of questions that were asked in the focus group interviews. The interview guide was not piloted tested and there were no follow-up interviews. Four interviewers (three women, one man; authors HT, SJ, ND, PG) were involved throughout the study with two interviewers present at each focus group. All interviewers were licensed clinical psychologists with over 10 years experience working with couples and/or patients with CVD. As the patient participants were former or current patients of the UOHI, a clinician-patient relationship was established prior to the data collection period for some participants $(n=4$; none of the partners were known). The focus of these relationships was individual care as part of cardiac rehabilitation. All participants were aware that the aim of the research was to ascertain patients' and partners' perspectives of intervention approaches that would be relevant to their needs. Although the interviewers have experience providing individual and couples-based interventions, the purpose of the research was to learn whether this would be of interest to the participants and what intervention components might be included.

\section{Data analysis}

Audio recordings of the focus groups were transcribed verbatim and subjected to directed and conventional content analysis, ${ }^{38}$ using a combination of deductive and inductive processes. Field notes were not taken. The transcribed focus groups were not returned to patients for comment or correction due to concerns regarding the sensitivity of the data (eg, medical history, relationship concerns) and previous research indicating that their 
corrections result in minimally higher data quality. ${ }^{39}$ All coding of the transcripts was conducted using N-Vivo Software. ${ }^{40}$ The focus group transcripts were subject to line-by-line coding and then similar codes were grouped into categories representing similar phenomena. General categories were defined by current research on patientpartner relationship quality, and newly emerging categories were added accordingly. Responses were coded by two independent researchers (MC and LM). Through discussing the categories with the first author (HT), the coders drew further analytic conclusions from the data; any discrepant items were discussed and resolved by consensus.

\section{PATIENT AND PUBLIC INVOLVEMENT}

Although patients or the public were not directly involved in the development of the research, the authors devised the interview questions based on their clinical experience working with patients with CVD and their partners. Conducting these focus groups was the first step towards creating a couple-oriented intervention to ensure patient engagement from the outset. Further, the results from the study were incorporated into a 'caregiver guide' that is provided to partners of patients at the UOHI on patient discharge from the hospital. The guide was developed in close consultation with executive members of the Patient Alumni Association at the UOHI, a patient group that represents over 12000 active members.

\section{RESULTS}

All patients that approached the researcher regarding participation met the eligibility criteria. The study included 16 cardiac patients and their partners $(n=32)$. Data saturation was reached with this sample size. ${ }^{41} 42$ Patients were mainly older ( $\mathrm{M}=64.4$ years, range $31-81$ years), white $(87.5 \%)$ and well-educated $(\mathrm{M}=14.86$ years). Twelve $(75 \%)$ of the patients with CVD were male, three were female and one couple both had a history of CVD. The cardiac diagnoses were varied: $50 \%$ had been diagnosed with coronary artery disease; $18.75 \%$ had valve disease; $18.75 \%$ had heart failure and $12.5 \%$ had arrhythmia. All couples were heterosexual. One couple dropped out of the study (patient was too distressed to speak about her heart condition).

Three focus groups were conducted, each with a maximum of six couples. The following categories that were generated from the analysis describe the nature of changes to the relationship that resulted from CVD: (1) emotional and communication disconnection; (2) overprotection of the patient; (3) role changes; (4) adjustment to lifestyle changes; and (5) positive relationship changes. Three categories emerged regarding the need for intervention and resources: (1) practical resources; (2) sharing with peers; and (3) relationship enhancement. These categories describe the participants' perceptions of what is required to adequately support couples managing CVD. See table 1 for the outcome categories and example quotes.

\section{Relationship changes}

Emotional and communication disconnection

The most prominent category that arose in the focusgroup discussions was a feeling of being disconnected emotionally and in communication patterns. The presence of CVD created added stress to the relationship, causing the patient and or the partner to become more irritable, increasing their propensity for conflict. A common cause for conflict was a newfound disconnection in communication, typically manifested by withdrawal or being 'shut down' emotionally. This often led to frustration, particularly among partners.

Partner 13: Totally frustrating, I'll say 'are you upset with me?' because I will talk or, or I will be talking about something and pouring my heart out, and he'll say 'did you see that truck over there?...' and I'll be like, he didn't even hear one word I said...it's kind of like he's in a bubble. So, sometimes I get very upset. I can get downright hostile about it, and sometimes I want to throw my hands up and say, that's it, I'm out of here. You need to be able to communicate, and meet each other where you are at, be honest about your relationship and be honest about how you feel, and if you are afraid, say something, not try to hide if from the other person.

Patient 07: I've become much more sensitive, like in terms of things that normally wouldn't bother me start to bother me now. I'm much more emotional a lot faster, and I think he struggles with that. We were used to a certain set of signals and now he doesn't know if it is coming or going. Her spouse added: One minute she can be really nice, and the other real nasty.

Partner01: You think you are coping...with a new way to cook or control portions and ensuring everyday physical activity, but then you forget to talk to each other.

\section{Overprotection of the patient}

As partners attempted to deal with the fear of potentially losing their loved one and an associated desire to keep them healthy to prevent another cardiac event, they became protective, often overprotective, leading to relationship conflict.

Patient 13: Even now, she said 'I'm not going to let you do anything.' Even in the truck she would stand on the ramp and say no....it is really a lot of reminding me what I can and can't do.

Partner 01: From the spouse point of view, we haven't lived in your position so we don't know, but we are there to help you, and sometimes it looks bad, or we're nagging, it's just we want what is best for you. 
Table 1 Outcomes of content analysis

Category Example quote

Changes to the relationship

Emotional and communication Partner 04: We have to slow down our conversations because we don't hear as fast as we disconnection used to, and I say something and he only listened to the first half and the second half is the most important. Then, he might get mad at me because I didn't do what he thought I said, I had said something else. We used to get along. Our daughter used to say that we do everything in short hand, and now we have to go back to long hand...I want to go back to what I had before.

Overprotection of the patient Patient 10: I try to get independence... 'I want to do this...' and she says 'well, you shouldn't do that' and I couldn't stay up at the cottage alone because it takes the paramedics too long, so I felt that my summer was a little hijacked. After the angioplasty, you tread on eggshells and that's the way it's gonna be now... I feel like a puppet on a string sometimes. His spouse replied: And, I feel like the ogre. I had to be the one who would say, 'you can't do that, or I can't let you do that.' I was some scared. It takes a long time getting over being scared to that degree.

Role changes

Partner 02: For me it's been a 6month full-time job, and that's my problem...something l've struggled with is doctors and nurses and support people saying "take care of yourself..." that is the most difficult thing in the world because there is no time to take care of yourself because you are looking after yourself and somebody else and life goes on... And for me, I managed fine for 3 months and after 3 months I all of a sudden realized I wasn't even breathing, so how can you rebalance, so what happens is, I get short tempered, intense and stressed.

Adjustment to lifestyle changes Patient 04: One of the things that we enjoy a whole lot together is ballroom dancing, and we got up to a fairly reasonably advanced level and, then all of a sudden with this heart issue, I didn't have the energy to stay upright for very much time at all. I would sit in one of the chairs on the side and [partner] would find herself busy dancing with an instructor, so at least she isn't sitting on the side as well, but it's so frustrating to not be able to do the things you used to be able to do before.

Positive relationship changes Patient 09: What [the cardiac event] has done actually, it has brought us closer together. I feel our relationship is stronger. From a selfish point of view, I am the one being taken care of. I have a 24 hours nurse. I feel it would be completely different if that even hadn't happened, who knows, we might have gone in different directions...now we do stuff together all the time... we try to see the positive side of things

Intervention needs and resources

Practical resources

Patient 12: I think some media to take home. Some pamphlets or DVDs or something. You could have like workshops for different things for couples.

Sharing with peers Partner 06: It's been a roller coaster, up and down, we tried to pick up the good moments and continue doing the right things... but it's tough. l'd like to learn more about other people and experiences and be able to share.

Relationship enhancement $\quad$ Partner 13: Sometimes people are secretive, and with [patient], he doesn't talk much. I've actually been to some of his rehab visits so that we have everything laid out and we are able to understand each other. I think communication is key to have people understand what's going on in your life, and sometimes you need that third party to get that communication going.

Patient 15: Sometimes it's nice to have an alarm [spouse] in your ear saying 'you shouldn't do that,' and you say thank you for the alarm, but in my mind this is the biggest emotional toll that there is.

Partner 07: She likes to dive in, and she gets so far into it she doesn't realize how far she's gotten in. I try to yell warning signs, but try to get her to listen... she's too headstrong, she'll do whatever she wants to do and it makes it difficult to warn her and it causes problems [between us] because of it.
Role changes and related stress

The onset of CVD led to changes in the roles each member assumed within the relationship on a day-to-day basis. One aspect of this was an increased caregiver burden and stress, where the increased responsibility of caring for the patient became a 'full-time job' for the partners.

Partner 10: Our children live [elsewhere], so it is basically just us, and when it comes down to it, it's basically just me...I continue to get stronger, but it has been heavy going, very stressful and very anxiety-making, 
and borderline situational depression or something like that, really just a different me inside, and it's coming back, but it's a piece of work.

Partner 16: I'm the one who maintains the menu, and the food buying and I feel very responsible about that...we've maintained a healthy diet, and that's good for both of us. I don't resent that, but I feel very responsible.

In contrast, patients with a cardiac condition tended to perceive a loss of their previous roles. Male patients especially felt that they were judged by those around them for not being able fulfil expected masculine social roles. One patient said that he felt 'worthless' and 'unimportant' as a result of not being able to 'perform' as a man. Patients expressed guilt for being an added burden to their partner and for having a decreased ability to support them.

Patient 05: There is definitely guilt involved. You put this on the other person. It's my heart problem, but now it's her problem...so, guilt is a big thing and you can hear the other person say 'It's ok, and its good and I love you and I support you,' but it's still guilt.

Patient 06: I don't think it's only the role of the man, you're expected to be working together...we went to Costco after the surgery and I couldn't move my arms, and you know, I was there with arms crossed, which is the most comfortable position, and my mother and wife were putting stuff on the cart and the cashier got so upset, and got up and went there and helped them and gave me the look.

\section{Adjusting to lifestyle changes}

It was apparent that the patient-partner relationship was impacted by the many lifestyle changes that were required following the onset of CVD. Many of the couples found that they needed to become accustomed to a "new normal', a loss of previous activity, and the presence of new restrictions to various aspects of their lives. Some couples lamented that they were not able to pursue personal or vocational activities they used to enjoy or joint activities that they did together:

Patient 07: I am struggling with taking pills everyday, that's not what I do. And, I know it sounds silly, but it difficult for me to know and admit that I have a problem, and that this is what I have to look forward to. Really, I'm very fortunate, but I'm struggling with some of that...the medication forces limitations on us, it's about the way we feel, and without it, what would our quality of life be, but it does change who we are and what we can do.

Partner 09: We were very active people, sports wise, and...culturally being members of the [arts venue], so with the bypass surgery we are not able to do all the activities that we had before. So our life has changed significantly.
Patient 01: People come up to you and say, 'oh, you look really good,' but yeah, you look good physically, but mentally you are still a jumble of all kinds of stuff. And, you are thinking between you and your partner, she should have a normal life, but now I've created an obstacle for her to carry on. And, when I go to work, I get tired and I sit down and everyone else is working and now you feel that you are not yourself anymore because you would be helping them before and now you're not because you are physically exhausted.

\section{Positive changes within the relationship}

In contrast, some couples expressed that the event brought them closer together and made their relationship even stronger, despite the changes that occurred in their lives as a result of the CVD. By working through the challenges of adjusting to their illness, they found new ways of showing affection and care for one another. Example statements include the following:

Partner 11: The [cardiac event] made us realize, even though we don't admit it to each other, how much we really do need each other. And it goes both ways.

Patient 09: Whatever you've had, that's an incident that opens the door that the relationship all of sudden has new facets, there are new things you find out about each other, strengths that you never realized about each other. You find out things that you probably wouldn't have told each other about your past. I think the incident is unique and it's a tool that can be used to strengthen a weak relationship or to reinforce one that is already fairly strong.

\section{Perceived needs and desired interventions}

Throughout the discussions, couples highlighted multiple needs and areas of potential intervention. Three themes emerged including: (1) practical resources and information; (2) the opportunity to share with peers; and (3) help with relationship enhancement. Further, all couples reported an interest in couples-based interventions. One participant noted that after dealing with three other major medical conditions, this was the first time anyone had asked about the needs of the patient and the partner. Patients and partners specifically requested that partners be involved in the care; one spouse pleaded 'include us in that training' when speaking about teachings for lifestyle and medication management. One patient felt that it was 'unfair' that spouses were not offered the programme he was in, especially because he had a positive experience 'connecting with the people in the rehab programme'.

\section{Practical information and resources}

Participants requested practical information to help them cope with CVD management such as workshops on stress management, medication management, healthy eating and generally what to expect when discharged from hospital. A recurrent theme was the importance of having information given to patients and partners about support they could be receiving. Spouses spoke about the need to 
repeat this information as they tended to be 'numb' after first learning of the cardiac event. Participants noted the need for intervention at various times, including while in hospital, at the time of hospital discharge, and in the months post discharge.

Partner 04: First, there is the shock, oh, it was a heart attack, and then in the hospital there is so much information, but I didn't get a lot of it because there is only so much I could take in my brain, because I had all this other stuff like 'what...it really was?'

Patient 02: We need information sessions and information on the [hospital] website.

Partner 02: Something I've struggled with is doctors and nurses and support people saying, 'take care of yourself'...but nobody says, 'this is a helpful way to take care of yourself...if you could do a, b, c...' for example, techniques for stress. A group to help learn new ways of doing something, even how to help yourself as your spouse recovers.

\section{Opportunity for sharing with peers}

The second area for intervention suggested by participants was the opportunity to meet and share experiences with other patients and partners coping with heart disease. This sharing was viewed as part of the healing process that could assist in normalising feelings, as well as provide an opportunity to learn from others' experiences and successes.

Patient 13: I think a support group would be good... sometimes you hear others and it kind of sparks something in you, you have a common ground you can talk about. I went to a support group after I left here to meet with people who had similar difficulties and I found that very helpful to meet with people who were having the same issues. Even a doctor who had never experienced it would probably not have the same input as patient to patient, because you really don't understand how a person feels until you've been there.

Partner 02: We have really sick spouses at some point who are very critical, and we get a lot of information about them, but it seems to me that the spouses themselves are also critical in this area...it would be wonderful to actually have some support groups for us because most often we don't know anybody else in the same critical situation and we flounder.

Partner 15: This kind of thing [group discussion] would have been really helpful in the beginning, to see what we are going through is normal and other people are too and it is normal.

\section{Relationship enhancement}

Lastly, participants spoke about a desire for assistance to enhance their relationship. As noted above, they were keenly aware of the changes in their relationship in light of the new stressor and wished to rebuild connections. They reported an interest in learning ways to communicate, reassure and help each other, in order to strengthen the relationship. In fact, one spouse recommended offering a phone line for couples to obtain counselling, noting that what they are dealing with is 'not just a health thing'.

Partner 12: I think it would have helped to know what I could do more to help, instead of fighting back or pushing him away.

Patient 09: I think the incident [cardiac event] is unique and it's a tool that can be used to strengthen a weak relationship, or reinforce one that is already fairly strong. If you were going to use a group, you might want to concentrate on that aspect rather than just the incident, we've all been through the painful part. More on how to rebuild and keep building or strengthen what you have. His spouse added: And, how to cope with the sensitivity of the other, and that he is not the same human being any more. The challenge is to stay close to this person that is so special to you as they change, and of course, as they change, so do you. His life has changed, but mine too.

Partner 04: We have this long relationship together. He contributes to my stuff and I contribute to his stuff...Finding out what is not so good is important as well as what's good so that we can capitalize on the good and try as much as possible to eliminate things that are not very good...so that is what we need to work on.

\section{DISCUSSION}

Using focus groups, this study explored relationship changes among patients with CVD and their partners. The data demonstrated that both patients and partners grappled with many adjustments to their relationship after the cardiac event, and were challenged to adapt to a 'new normal'. Similar to previous studies, ${ }^{25}{ }^{36}$ our findings call attention to the emotional and communication disconnection between partners, and distress related to role changes, lifestyle adjustments and overprotective behaviours. Like other studies, ${ }^{25}{ }^{36}$ we also observed a silver lining to the CVD cloud-the strengthening of the couple bond. Possibly the most novel aspect of our study, however, was the exploration of needs and desired areas of intervention proposed by participants. To our knowledge, only one other study engaged patients with CVD (ie, heart failure) and their partners on this topic, particularly regarding information and education support. ${ }^{28}$ While our participants noted value in instrumental support and practical resources, they clearly communicated the importance of assistance in building connections with their peers and partners to help them cope. Our results underscore the need for interventions that target both members of the dyad, instead of the current status quo which, for the most part, includes only the patient in care.

A systematic review by Dalteg et alfound that the themes of overprotection, communication deficiency, sexual concerns, changes in domestic roles and adjustment to 
illness were the most common themes across 20 different studies. ${ }^{25}$ These themes, except sexual concerns, were major topics that arose in the focus groups conducted in this study. Similar to findings from a study of couples managing atrial fibrillation, ${ }^{26}$ we also observed that some couples would collaborate and agree on adjustments in lifestyle as a way to cope with uncertainty. Developing shared appraisals of a stressor and (ie, viewing a problem as 'ours' vs 'yours') and then engaging in collaborative problem solving has been described as a process of communal coping. ${ }^{43}$ Burgeoning evidence indicates that these shared appraisals may facilitate better adjustment to chronic illness and improve health behaviours. ${ }^{44}$

In contrast, many of the patient participants described distancing themselves from their partners in an attempt to protect their partner from distress or worry. Further, our findings indicated that a cardiac event changed the communication and emotional aspects within the relationship as well as the logistical aspects of everyday habits, activities and roles. Any change in circumstance in any of these aspects for one partner would inevitably affect similar aspects of the other partner, as well as the identity of the couple. Each member of the couple needed to relearn aspects of each other in order to reduce conflict and sustain the relationship.

Evidence continues to link poor spousal relationships to worsened cardiovascular health and negative behaviours affecting CVD outcomes ${ }^{45}$; as such, screening and monitoring changes in patient-partner relationship quality may be an important task for clinicians. Box 2 provides some suggested questions that clinicians and other healthcare professionals may use to inquire about changes to the patient-partner relationship. Further, when couples spoke about what they would find useful in a couples-based intervention, several individuals mentioned the benefit of meeting other couples with similar experiences and learning strategies to improve their relationship in order to help the other person cope with CVD management.

Some patients seemed to have an ambivalent attitude towards their partners who have taken more of a policing and caregiver role. It was clear that, although they appreciated the support they received, it was a cause of stress and guilt for patients as well. Uchino $e t a l^{46}$ found that

Box 2 Potential questions for clinicians and healthcare professionals to ask patients and partners

1. It is common for your relationship to change after experiencing a heart event. Have you noticed any changes to your relationship with your spouse?

2. Have changes to your relationship with your spouse made it more difficult for you to cope with the challenges of heart disease?

3. What do you and your partner do to help promote a positive relationship with each other?

4. What would you and your partner require to help you cope better together? members of couples who felt ambivalently towards their spouse were less likely to seek or benefit from the support of their relationship; this ambivalence was related to increased CVD risk factors. Clinically, this suggests that the presence of discord in the relationships of cardiac patients, as was found in the present study, may increase their risk of recurrent disease and result in poorer quality of life for this population.

It is apparent that partners have been neglected and deprived of care to date, despite their clear contribution to our healthcare system. ${ }^{478}$ This fact is disturbing considering the mounting evidence to suggest that partners of patients with CVD are also vulnerable to developing poorer health outcomes, such as increased distress and depressive symptoms, higher blood pressure, weight gain and disordered sleep. ${ }^{49}{ }^{50}$ In fact, research shows up to $25 \%$ of partners of patients with CVD experience symptoms of post-traumatic stress. ${ }^{51}$ In our focus groups, it was evident that many of the partners provided care without the adequate resources to do so and were more isolated than the patient in facing the uncertainty of the CVD they were helping to manage. Despite the psychological benefits of cardiac rehabilitation, ${ }^{1}$ partners of patients with CVD are often excluded from this important intervention. The present study shows the vital role of partners in the care of cardiac patients; thus, it is important to recognise that providing support to partners is critical for both partners' psychosocial and medical health outcomes. ${ }^{30}$

\section{LIMITATIONS}

This study is not without limitations. First, although the sex distribution is similar to that of the cardiac rehabilitation population, the majority of the patient participants were heterosexual males, potentially biassing the data by sex and preventing meaningful analyses between the sexes. Second, the data were collected from one cardiac centre in Canada; an exploration of needs and desires of this population in other centres would strengthen our findings. It is important to note, however, that the systematic review of 20 studies from various countries identified similar categories. ${ }^{25}$ Third, a clinician-patient relationship existed with four of the patient participants, but not their partners. Although conventional content analysis assumes that there are multiple perspectives of the data and that the researchers' positionality (ie, their thoughts and feelings towards the data, subject matter and participants) necessarily influences the data analysis, ${ }^{38}$ one must be mindful of how their relationship to the participant the topic may ultimately shape their interpretation of the data. Fourth, we did not record the range of years that participants were in their couple relationship. Future research would do well to collect this information and investigate whether this variable influences the themes reported. Fifth, since the interviews were conducted at one time point only, the findings cannot reveal how intimate relationships and participants' needs may change over time. As the effects on martial satisfaction may be 
different depending on the cardiac illness timeline, ${ }^{52}$ future studies employing a longitudinal design may be beneficial. Sixth, although our inclusion of patients with CVD of any diagnostic group builds on previous research with select CVD populations and provides a starting point for the general understanding of couples' needs, it precludes an evaluation of the unique needs specific to one diagnostic group. Future research with a larger number of dyads from many diagnostic groups may uncover different needs highlighted by each group. Lastly, focus groups were used to facilitate interaction and discussion among participants; however, this format may inhibit sharing of some intimate information. As such, we recommend that focus groups be augmented with individual interviews in future studies. Despite these limitations, this is the first study that explored, in depth, the desired intervention components of patients and their partners to help them better manage CVD. Findings allowed for the elucidation of strengths and weaknesses in cardiac rehabilitation programming and better determine the needs of this patient population and their partners.

\section{CONCLUSION}

In summary, the present study demonstrated that the acute onset and chronic effects of CVD cause both positive and negative changes to the couples' relationship. The results highlight the need for more specialised couplesbased interventions that aid both patients and their partners through the new reality of living with CVD. Changes within the relationship are inevitable after a cardiovascular event; therefore, it is essential to support couples as they cope with these changes in ways that strengthen their connections to peers and each other and improve their health.

\section{IMPLEMENTATIONS FOR PRACTICE}

- Partners should be actively included in interventions aimed at improving recovery of patients with CVD. Practical resources, opportunities to share with peers and couples-based interventions are required.

- Changes to patients' and partners' relationship quality should be assessed within cardiac rehabilitation programming and action taken to support patients and partners in strengthening their relationship.

- Future research should investigate whether couplesbased programming is effective in reducing both partners' stress brought on by CVD and whether meaningful changes to relationship quality and clinical outcomes are observed as a result of participating in such couples-based programming.

\section{Author affiliations}

${ }^{1}$ Division of Cardiac Prevention and Rehabilitation, University of Ottawa Heart Institute, Ottawa, Ontario, Canada

${ }^{2}$ Western University, London, Ontario, Canada

${ }^{3}$ Ottawa Hospital, Ottawa, Ontario, Canada
${ }^{4}$ Ottawa Couple and Family Institute, Ottawa, Ontario, Canada

${ }^{5}$ Département de Psychoéducation et de Psychologie, Universite du Quebec en Outaouais, Gatineau, Quebec, Canada

Twitter Heather Tulloch @HeartInstitute, Karen Bouchard @karen_bouchard and Lorenzo Madrazo @LorenzoMadrazo

Funding This work was supported by a research grant from the International Centre for Excellence in Emotionally Focused Therapy.

Competing interests None declared.

Patient and public involvement Patients and/or the public were not involved in the design, or conduct, or reporting, or dissemination plans of this research.

Patient consent for publication Not required.

Ethics approval The Ottawa Health Science Network Research Ethics Board deemed this study as a quality assurance/improvement project; therefore, full ethics review was not required, but approval was granted to publish these data.

Provenance and peer review Not commissioned; externally peer reviewed.

Data availability statement № data are available.

Open access This is an open access article distributed in accordance with the Creative Commons Attribution Non Commercial (CC BY-NC 4.0) license, which permits others to distribute, remix, adapt, build upon this work non-commercially, and license their derivative works on different terms, provided the original work is properly cited, appropriate credit is given, any changes made indicated, and the use is non-commercial. See: http://creativecommons.org/licenses/by-nc/4.0/.

ORCID iD

Heather Tulloch http://orcid.org/0000-0001-7466-8554

\section{REFERENCES}

1 Shepherd CW, While AE. Cardiac rehabilitation and quality of life: a systematic review. Int J Nurs Stud 2012;49:755-71.

2 Valtorta NK, Kanaan M, Gilbody S, et al. Loneliness and social isolation as risk factors for coronary heart disease and stroke: systematic review and meta-analysis of longitudinal observational studies. Heart 2016;102:1009-16.

3 Holt-Lunstad J, Smith TB, Layton JB. Social relationships and mortality risk: a meta-analytic review. PLoS Med 2010;7:e1000316.

4 Reid J, Ski CF, Thompson DR. Psychological interventions for patients with coronary heart disease and their partners: a systematic review. PLoS One 2013;8:e73459.

5 Barger SD, Cribbet MR. Social support sources matter: increased cellular aging among adults with unsupportive spouses. Biol Psychol 2016;115:43-9.

6 Manfredini R, De Giorgi A, Tiseo R, et al. Marital status, cardiovascular diseases, and cardiovascular risk factors: a review of the evidence. J Womens Health 2017;26:624-32.

7 Hayes RM, Carter PR, Gollop ND, et al. The impact of marital status on mortality and length of stay in patients admitted with acute coronary syndrome. Int J Cardiol 2016;212:142-4.

8 Gottman J, Gottman J. The natural principles of love. J Fam Theory Rev 2017;9:7-26.

9 Smith T, Baron C. Marital discord in the later years. In: Bookwala J, ed. Couple relationships in the middle and later years: their nature, complexity, and role in health and illness. American Psychological Association, 2016.

10 Uchino BN. Social support and health: a review of physiological processes potentially underlying links to disease outcomes. J Behav Med 2006;29:377-87.

11 Robles TF, Slatcher RB, Trombello JM, et al. Marital quality and health: a meta-analytic review. Psychol Bull 2014;140:140-87.

12 Smith TW, Uchino BN, Berg CA, et al. Marital discord and coronary artery disease: a comparison of behaviorally defined discrete groups. J Consult Clin Psychol 2012;80:87-92.

13 Eaker ED, Sullivan LM, Kelly-Hayes M, et al. Marital status, marital strain, and risk of coronary heart disease or total mortality: the Framingham offspring study. Psychosom Med 2007;69:509-13.

14 King KB, Reis HT. Marriage and long-term survival after coronary artery bypass grafting. Health Psychol 2012;31:55-62.

15 Robles TF, Kiecolt-Glaser JK. The physiology of marriage: pathways to health. Physiol Behav 2003;79:409-16.

16 Birditt KS, Newton NJ, Cranford JA, et al. Stress and negative relationship quality among older couples: implications for blood pressure. J Gerontol B Psychol Sci Soc Sci 2016;71:775-85. 
17 Cundiff JM, Birmingham WC, Uchino BN, et al. Marital quality buffers the association between socioeconomic status and ambulatory blood pressure. Ann Behav Med 2016;50:330-5.

18 Trevino DB, Young EH, Groff J, et al. The association between marital adjustment and compliance with antihypertension regimens. J Am Board Fam Pract 1990;3:17-25.

19 Rankin-Esquer LA, Deeter AK, Froeliche E, et al. Coronary heart disease: intervention for intimate relationship issues. Cogn Behav Pract 2000;7:212-20.

20 Hooker SA, Grigsby ME, Riegel B, et al. The impact of relationship quality on health-related outcomes in heart failure patients and informal family caregivers: an integrative review. J Cardiovasc Nurs 2015;30:S52-63.

21 Randall G, Molloy GJ, Steptoe A. The impact of an acute cardiac event on the partners of patients: a systematic review. Health Psychol Rev 2009;3:1-84.

22 Martire LM, Schulz R, Helgeson VS, et al. Review and meta-analysis of couple-oriented interventions for chronic illness. Ann Behav Med 2010;40:325-42.

23 Martire LM, Lustig AP, Schulz R, et al. Is it beneficial to involve a family member? A meta-analysis of psychosocial interventions for chronic illness. Health Psychol 2004;23:599-611.

24 Sher T, Braun L, Domas A, et al. The partners for life program: a couples approach to cardiac risk reduction. Fam Process 2014;53:131-49.

25 Dalteg T, Benzein E, Fridlund B, et al. Cardiac disease and its consequences on the partner relationship: a systematic review. Eur $J$ Cardiovasc Nurs 2011;10:140-9.

26 Dalteg T, Benzein E, Sandgren A, et al. Managing uncertainty in couples living with atrial fibrillation. $J$ Cardiovasc Nurs 2014:29:E1-10.

27 Kim JSR, Risbud R, Gray C, et al. The Dyadic experience of managing heart failure: a qualitative investigation. $J$ Cardiovasc Nurs 2020;35:12-18.

28 Liljeroos M, Agren S, Jaarsma T, et al. Perceived caring needs in patient-partner dyads affected by heart failure: a qualitative study. $J$ Clin Nurs 2014:23:2928-38.

29 Nissen NK, Jónsdóttir M, Spindler H, et al. Resistance to change: role of relationship and communal coping for coronary heart disease patients and their partners in making lifestyle changes. Scand $J$ Public Health 2018;46:659-66.

30 Pretter S, Raveis VH, Carrero M, et al. Couples living with cardiovascular disease: effects on the marital relationship. J Fam Soc Work 2014;17:21-36.

31 Rowland SA, Schumacher KL, Leinen DD, et al. Couples experiences with healthy lifestyle behaviors after cardiac rehabilitation. J Cardiopulm Rehabil Prev 2018;38:170-4.

32 Liljeroos M, Ågren S, Jaarsma T, et al. Long term follow-up after a randomized integrated educational and psychosocial intervention in Patient-Partner dyads affected by heart failure. PLoS One 2015;10:e0138058.

33 Cameron J, Thompson DR, Szer D, et al. Dyadic incongruence in chronic heart failure: Implications for patient and carer psychological health and self-care. J Clin Nurs 2017;26:4804-12.
34 Czajkowski SM, Powell LH, Adler N, et al. From ideas to efficacy: the orbit model for developing behavioral treatments for chronic diseases. Health Psychol 2015;34:971-82.

35 Kitzinger J. The methodology of focus groups: the importance of interaction between research participants. Sociol Health IIIn 1994;16:103-21.

36 Arenhall E, Kristofferzon M-L, Fridlund B, et al. The male partners experiences of the intimate relationships after a first myocardial infarction. Eur J Cardiovasc Nurs 2011:10:108-14.

37 Arenhall E, Kristofferzon M-L, Fridlund B, et al. The female partners' experiences of intimate relationship after a first myocardial infarction. $J$ Clin Nurs 2011b;20:1677-84.

38 Hsieh H-F, Shannon SE. Three approaches to qualitative content analysis. Qual Health Res 2005;15:1277-88.

39 Hagens V, Dobrow MJ, Chafe R. Interviewee transcript review: assessing the impact on qualitative research. BMC Med Res Methodol 2009;9:47.

40 QSR International. NVivo [computer program]. Version 10. Australia; 2014.

41 Guest G, Namey E, McKenna K. How many focus groups are enough? building an evidence base for nonprobability sample sizes. Field methods 2017;29:3-22.

42 Hennink MM, Kaiser BN, Weber MB. What influences saturation? estimating sample sizes in focus group research. Qual Health Res 2019;29:1483-96.

43 Rentscher KE. Communal coping in couples with health problems. Front Psychol 2019;10:398.

44 Helgeson VS, Jakubiak B, Van Vleet M, et al. Communal coping and adjustment to chronic illness: theory update and evidence. Pers Soc Psychol Rev 2018;22:170-95.

45 Whisman MA, Uebelacker LA, Settles TD. Marital distress and the metabolic syndrome: linking social functioning with physical health. $J$ Fam Psychol 2010;24:367-70.

46 Uchino BN, Smith TW, Berg CA. Spousal relationship quality and cardiovascular risk: dyadic perceptions of relationship ambivalence are associated with coronary-artery calcification. Psychol Sci 2014;25:1037-42.

47 Parry M, Burden C. Caregiver burden and cardiovascular disease: can we afford to keep the health of caregivers in Canada invisible? Can J Cardiol 2019;35:1267-9.

48 Revenson T, Griva K, Luszczynska A, et al. Caregiving in the illness context. New York, NY: Palgrave Macmillan, 2016.

49 Adelman RD, Tmanova LL, Delgado D, et al. Caregiver burden: a clinical review. JAMA 2014;311:1052-60.

50 Burton LC, Newsom JT, Schulz R, et al. Preventive health behaviors among spousal caregivers. Prev Med 1997;26:162-9.

51 Vilchinsky N, Unrecognized VN. Unrecognized, undiagnosed, and untreated: Cardiac-Disease-Induced PTSD among patients' partners. Front Psychol 2017;8:1265.

52 Dekel R, Vilchinsky N, Liberman G, et al. Marital satisfaction and depression among couples following men's acute coronary syndrome: testing dyadic dynamics in a longitudinal design. $\mathrm{Br} J$ Health Psychol 2014;19:347-62. 